\title{
Polymorphisms in leucine-rich repeat genes are associated with autism spectrum disorder susceptibility in populations of European ancestry
}

\author{
Inês Sousa1, Taane G Clark1,2, Richard Holt1', Alistair T Pagnamenta1, Erik J Mulder3, Ruud B Minderaa3, \\ Anthony J Bailey4, Agatino Battaglia5, Sabine M Klauck6, Fritz Poustka7, Anthony P Monaco*1 and International \\ Molecular Genetic Study of Autism Consortium (IMGSAC)
}

\begin{abstract}
Background: Autism spectrum disorders (ASDs) are a group of highly heritable neurodevelopmental disorders which are characteristically comprised of impairments in social interaction, communication and restricted interests/ behaviours. Several cell adhesion transmembrane leucine-rich repeat (LRR) proteins are highly expressed in the nervous system and are thought to be key regulators of its development. Here we present an association study analysing the roles of four promising candidate genes - LRRTM1 (2p), LRRTM3 (10q), LRRN1 (3p) and LRRN3 (7q) - in order to identify common genetic risk factors underlying ASDs.

Methods: In order to gain a better understanding of how the genetic variation within these four gene regions may influence susceptibility to ASDs, a family-based association study was undertaken in 661 families of European ancestry selected from four different ASD cohorts. In addition, a case-control study was undertaken across the four LRR genes, using logistic regression in probands with ASD of each population against 295 ECACC controls.
\end{abstract}

Results: Significant results were found for $\angle R R N 3$ and LRRTM3 $(P<0.005)$, using both single locus and haplotype approaches. These results were further supported by a case-control analysis, which also highlighted additional SNPs in LRRTM3.

Conclusions: Overall, our findings implicate the neuronal leucine-rich genes $\angle R R N 3$ and $L R R T M 3$ in ASD susceptibility.

\section{Background}

Autism is a genetically complex neurodevelopmental disorder, characterized by impairments in reciprocal social interaction and communication, along with restricted and stereotyped patterns of interests and behaviours [1]. It is an extremely heterogeneous and highly heritable condition, affecting predominantly males (with an average sex ratio of $4: 1$ ), and with an onset before 3 years of age [2,3]. Autism spectrum disorders (ASDs) refers to a broad definition of autism, including classical and atypical autism, Asperger syndrome and pervasive developmental disorder not otherwise specified [4]. The aetiology of ASD is not fully under-

\footnotetext{
* Correspondence: anthony.monaco@well.ox.ac.uk

1 Wellcome Trust Centre for Human Genetics, University of Oxford, Oxford OX3 7BN, UK

Full list of author information is available at the end of the article
}

stood and the causal variants and their modes of transmission remain elusive.

Leucine-rich repeats (LRRs) are common protein-protein interaction motifs and are typically 20-29 amino acids in length [5]. LRR proteins are highly expressed in the nervous system and are involved in numerous biological functions, including nervous system development [5-10]. Mutations in LRR genes have been associated with different diseases, such as hereditary lateral temporal epilepsy [11] and Parkinson disease [12]. Furthermore, a recent study suggested that LRR variants could possibly be involved in ASD susceptibility [13].

From the 313 known human LRR genes (NCBI Build 36.1), this work focused on four brain-enriched LRR candidates - LRRTM1, LRRTM3, LRRN1 and LRRN3. There are several LRR subfamilies, differentiated by the consensus sequence of the repeat and/or different combinations of 
supplementary domains $[5,8,14]$. One family of brainenriched LRR containing type I transmembrane proteins is termed the LRRTM (leucine rich repeat transmembrane neuronal) family [8]. This is a highly conserved four-member family which, with the exception of LRRTM4, has the unusual characteristic of being located in the introns of different $\alpha$-catenin genes. Catenin family members are adhesion proteins that can form a complex with cadherins, which themselves have also been implicated in intellectual disability, autism and ASD risk [13,15-17]. LRRTM messenger (m)RNAs are mainly expressed in the nervous system, each with a distinct and highly regulated pattern $[8,18]$. It has recently been proposed that LRRTMs are synaptic organizing molecules and synaptogenic inducers in neurons, initiating excitatory presynaptic differentiation and mediating post-synaptic specializations [19]. As several synaptic genes have been implicated in ASD, these genes become promising candidates to study [20].

LRRTM1 (MIM*610867), located on 2p12, lies within intron 7 of CTNNA2 ( $\alpha 2$-catenin) with the highest mRNA expression in the brain and salivary gland [8]. LRRTM1 is the first gene to be associated with both human handedness (relative hand skill) and schizophrenia [21] and is thought to be involved in brain development, neuronal connectivity, intracellular trafficking in axons and synaptogenesis $[19,21]$. Therefore, it is an interesting candidate for autism where there is already some evidence for associations with abnormal asymmetrical brain structure in language-associated areas [22,23].

Similarly, LRRTM3 (MIM*610869), on 10q22.1, is positioned within intron 7 of CTNNA3 ( $\alpha$ T-catenin). This gene has a more restricted expression profile compared to $L R R T M 1$, with expression in the brain, particularly the cerebellum [8,24]. In addition, LRRTM3 is functionally and positionally linked to late-onset Alzheimer's disease [24,25]. Moreover, CTNNA3 has also been recently suggested to be associated to ASD susceptibility [13].

The LRRN (leucine rich repeat neuronal) family of proteins has four known members in humans, all being brainenriched type I transmembrane proteins [26]. Studies in several species show that the members of this family have different spatial and temporal expression patterns and that they are involved in neural development and regeneration [14,27-29]. Although they seem to function as adhesion molecules or binding receptors in regulatory mechanisms, their biological activities and specific central nervous system (CNS) functions in humans are still unclear [30,31].

$L R R N 1$, located on $3 \mathrm{p} 26.2$, is again a nested gene located in intron 8 of the long form of SUMF1 (sulphatase modifying factor 1) (NM_182760). In the developing neural cells of the chick, Lrrn1 is localized in the endosome, suggesting that it might be involved in the regulation of cell adhesion and signalling pathways [32]. LRRN1 shows a high degree of sequence conservation and comparison to its expression in the mouse indicates that it is dynamically expressed in the somites and the neural plate during development, and mostly in the brain and kidney in the adult [14]. Furthermore, $L R R N 1$ is located within a candidate region for recessive non-syndromic mental retardation on chromosome 3 [33]. Additionally, a paternally inherited duplication (3p26.1-26.2) which encompasses LRRN1 was reported in children with autism and additional developmental abnormalities [34].

Finally, LRRN3 maps to $7 \mathrm{q} 31.1$ and is brain-enriched [14,31,35]. LRRN3 is a nested gene in IMMP2L (inner mitochondrial membrane peptidase-like), being positioned within intron 3. The molecular structure and expression pattern of Lrrn3, suggest that it plays a role in the development and maintenance of the nervous system [14]. Other studies have shown that Lrrn3 exhibits regulated expression in the developing ganglia and motor neurons of the neural system, and is upregulated during neuronal cortical injury $[14,27,28]$. In addition, one of the most consistently replicated loci for autism, first identified by The International Molecular Genetic Study of Autism Consortium (IMGSAC) [36], is on 7q21.3-7q34 [37-43]. As LRRN3 is located under the linkage peak of interest for IMGSAC families, and there is evidence of an association with the $I M M P 2 L /$ DOCK4 region in the IMGSAC cohort [44], we considered $L R R N 3$ to be an appealing candidate for ASD susceptibility, despite a previous study failing to find evidence of an association between this gene and autism in their cohorts [45].

Here, the roles of LRRTM1, LRRTM3, LRRN1 and $L R R N 3$ in ASD susceptibility were studied in four different populations of European ancestry (IMGSAC, Italian, German and Northern Dutch). The variation at these four loci was assessed and the association of gene variants and haplotypes with ASD was tested in a family based study. Significant evidence of their association to ASD was found for $L R R N 3$ and LRRTM3. In order to complement this analysis, a case-control study was performed, partially supporting the evidence of association found in LRRN3 and LRRTM3. To our knowledge, this is one of the most comprehensive genetic analyses of association between these genes and ASD risk.

\section{Methods \\ Subjects}

All the individuals who participated in this study are Caucasian and of European ancestry. Four cohorts were used, our core IMGSAC set consisting mainly of UK families, two groups from Italy and Germany (collected as part of the IMGSAC collaboration) and a population from the north of the Netherlands. These cohorts are referred to as IMGSAC, Italian, German and Northern Dutch, respectively. A total of 2758 individuals from 661 families [439 IMGSAC ( 350 multiplex and 89 singleton), 85 Italian, 30 German and 107 Northern Dutch] were analysed. The male:female ratio of 
the affected individuals is 4.1:1. Also, a cohort of 295 UK DNA controls [European Collection of Cell Cultures $($ ECACC]) was used for the case-control study. ECACC controls were randomly selected, non-related, UK Caucasian blood donors http://www.hpacultures.org.uk/products/ dna/hrcdna/hrcdna.jsp. For the IMGSAC sample collection the identification of families, assessment methods and inclusion criteria used have been described previously [37]. Briefly, after identification in an initial screen for autism, parents undertook the Autism Diagnostic InterviewRevised (ADI-R) [46] and the Vineland Adaptive Behaviour Scales [47]. Probands were assessed using the Autism Diagnostic Observation Schedule (ADOS) [48] and a clinical evaluation was undertaken in order to exclude known medical disorders aetiologically associated with autism (for example, tuberous sclerosis and neurofibromatosis). Karyotypes were obtained for probands when possible and molecular genetic testing for fragile $\mathrm{X}$ syndrome carried out on one affected case per family. A blood sample was taken from both probands and available first degree relatives. DNA was extracted from blood samples, buccal swabs or cell lines using a DNA purification kit (Nucleon ${ }^{\circledR}$ BACC2 Blood and Cell Culture DNA purification kit, Tepnel Life Sciences, Manchester, UK) and standard techniques. The Italian and German populations had the same assessment as that described above as they are part of the wider IMGSAC group. For the Northern Dutch population the subjects and their assessment are again described in detail elsewhere [49]. In short, the families were recruited through an epidemiological survey and an autism outpatient clinic affiliated with the Child and Adolescent Psychiatry Center of Groningen. The diagnosis criteria were very similar to those previously described for IMGSAC (including ADI-R and ADOS assessments) and the children's intellectual functioning was evaluated as described by Mulder et al. [50]. DNA was extracted from cheek cells obtained by mouth swabs from patients, parents and siblings using the Epicentre Master$\mathrm{Amp}^{\mathrm{TM}}$ DNA Extraction Solution Kit (BiozymTC, Landgraaf, the Netherlands). The study was reviewed by the relevant ethical committees. For IMGSAC population cohort the ethical approval was carried out by:

(a) Europe (UK - Oxfordshire Psychiatric Research Ethics Committee A, under the review number O03.013 and title name 'Identifying and understanding the actions of autism susceptibility genes'; Cambridge Local Research Ethics Committee; Institute of Psychiatry Ethical Research Committee; Joint Ethics Committee (Newcastle \& North Tyneside Health Authority/Universities of Newcastle upon Tyne/Northumbria); Salford and Trafford Research Ethics Committee/Denmark - Den Videnskabsetiske Komite, Kobenhavns Amt/Finland - Ethical Committee for the Hospital of Children and Adolescents and Psychiatry (University Central Hospital)/France - Comité Consultatif de Protection des Personnes dans la Recherche Biomédicale
Groupe Hospitalier Pitié-Salpêtrière-Paris/Germany Ethik-Kommission des Fachbereichs Medizin der Johann Wolfgang Goethe (Universität Frankfurt am Main); Heidelberg Ethikkommission der Medizinischen Fakultät/Greece Agia Sophia Hospital Ethics Committee/Italy - Comitato Etico IRCCS Fondazione Stella Maris/Netherlands Medisch Ethische Toetsingscommissie/Sweden - Ethical Review Board of Sahlgren's Academy, Goteborg University Faculty of Medicine

(b) USA - Yale University School of Medicine Human Investigation Committee; University of Illinois at Chicago's Office for the Protection of Research Subjects; University of Michigan Medical School IRBMED

(c) Canada - The Hospital for Sick Children, Research Ethics Board; Hamilton Health Sciences/McMaster University Research Ethics Board.

For the Northern Dutch population cohort, ethical review was done by the Medical Ethical Committee of the University Medical Center Groningen under review number M08.057360.

Written informed consent was provided by all parents/ guardians and, when possible, by the affected individuals. The IMGSAC cases are Caucasian, but from different sites in Europe and the USA. Therefore, population substructure is a distinct possibility. The samples used for the current study have substantial overlap with the IMGSAC samples described in Maestrini et al. [44], where no evidence of strong population stratification was detected. However, it is possible that subtle or low levels of population stratification may be present, potentially leading to false positives in the case-control analysis.

\section{Genotyping \\ Single nucleotide polymorphism (SNP) selection}

Genotyping data from Centre d'Etude du Polymorphisme Humain individuals was downloaded from the HapMap phase II (release 24) for each gene and approximately $5 \mathrm{~kb}$ of upstream and downstream sequence. This resulted in information for the four following regions being obtained: 2p12 (80381256-80386255); 10q22.1 (6835304568532626); 3p26.2 (3814162-3866687); and 7q31.1 (110516705-110554408). Sixty-seven haplotype tagging SNPs were chosen across these loci using Tagger from Haploview v4.0 [51] $\left[r^{2}>0.8\right.$ and minor allele frequency (MAF) $>0.05$, aggressive tagging], capturing the maximum amount of genetic variation in the four regions. In addition, one 3'untranslated region and two synonymous SNPs in LRRTM1 were genotyped, as these were the only markers left to genotype in order to complete the whole coverage of this region.

\section{Sequenom assay}

The genotyping assay was designed using the MassARRAY software (Sequenom) and genotypes obtained using the MassARRAYTyper ${ }^{\mathrm{TM}}$ system (version 3.1.4.0). Quantifica- 
tion of DNA samples was performed using the Picogreen ${ }^{\circledR}$ dsDNA Quantitation Kit (Invitrogen, Oregon, USA) and $40 \mathrm{ng}$ of genomic DNA per sample was used in the genotyping assay. Genotyping was performed using the Sequenom MALDI-TOF iPLEX platform (Sequenom, San Diego, USA). The sample and marker genotyping success rates were $\sim 98 \%$ and $94 \%$, respectively. Based on two control samples included on each plate as genotyping controls, we found high inter-plate reproducibility (99.8\%). Genotype Analyzer (Sequenom) was used to visually check the quality of each genotype call, assigning alleles where possible. An in-house database [52] was used to store all genotypic data and to produce files for statistical analysis.

\section{Statistical analysis Error checking}

Genotypes were checked for Mendelian consistency using PedCheck [53] and any inconsistent genotypes were removed. Genotypes flanking double recombinants were detected using MERLIN [54] and, in ambiguous cases where probable excess recombination occurred, genotypes were reconfirmed and corrected as necessary. All the SNPs were tested for Hardy-Weinberg equilibrium using a $\chi^{2}$ test, in parents and probands separately.

\section{Association analysis}

The pairwise linkage disequilibrium (LD) maps for $L R R N 1$, $L R R N 3$ and LRRTM3 were constructed from genotypes using the Haploview software (Figure 1). SNP and haplotype association in families was assessed using the transmission disequilibrium test (TDT) [55], with a version robust to non-independent siblings implemented [56], allowing for the use of multiple siblings within a nuclear family. Allele frequencies were reported for all the parents and children. From applying the TDT, the allele transmission frequencies from parents to offspring were also estimated. Parental transmissions were also analysed for each SNP to consider parent-of-origin effects. In order to combine the evidence across all cohorts at each polymorphism, we estimated odds ratios (ORs) and their standard errors from transmission frequencies [57] and then performed a meta-analysis pooling using an inverse variance approach [58]. Also, at each polymorphism we performed a chisquare test of heterogeneity of the ORs [58]. Meta-analysis forest plots were constructed for each marker using the meta library in the R statistical software http:/www.r-project.org. A haplotype-based TDT analysis was also carried out using TRANSMIT [56]. For each haplotype, risk estimates and their $95 \%$ credibility internals were estimated using a Bayesian method [55,56]. Logistic regression was used in the analysis of both the alleles and genotypes in the case-control study. When we were analysing cases from the same family, we performed a weighted logistic analysis where each family contributed the same weight. In the logistic regression framework, testing on the genotypes (for example, dd, DD and Dd) without regard to any 'order', allelic count or allelic pairing was performed. In particular, we investigated several related genotypic mechanisms: (i) an additive model which assesses the influence of increasing the number of minor alleles $(0,1,2)$ on log-risk; (ii) dominant model (of the 'd' allele: dd/Dd versus DD); (iii) recessive model (of ' $d$ ': dd versus Dd/DD); (iv) heterozygous advantage (Dd versus DD/dd); (v) general model (dd versus DD, Dd versus DD). We report the minimum $P$ value from these correlated tests. Meta-analytic approaches were also applied to pool the resulting allele- and genotypebased ORs across populations.

\section{Multiple testing correction}

Performing multiple statistical tests leads to inflation in the occurrence of false positives and it is therefore necessary to adjust the statistical significance ( $P$-value) threshold (usually $5 \%$ ) in order to account for the number of independent tests. A Bonferroni correction using the total number of SNPs would be too conservative because of the high LD between SNPs in the analysed regions [56]. By considering the LD pattern, which identified 10 independent haplotype blocks, it is reasonable to interpret using a $P<0.005$ (= $0.05 / 10$ ) to be statistically significant. Using a separate permutation approach we found a similar (5\%) significance threshold $(P<0.0048)$ based on inference of the maximum chi-square statistic observed over all genotyped SNPs. In particular, both the transmitted/untransmitted and case-control status of the chromosomes were randomly permuted 10,000 times. From each of the 10,000 random experiments, in both trio and case-control studies, we determined the maximum chi-square statistics over all SNPs genotyped. We ordered these statistics and then calculated the 95 percentile. This was the estimate of the 0.05 significance level for the experiment performed, assuming inference is taken with respect to maximum chi-square statistic observed over all genotyped SNPs.

\section{Results}

\section{Family-based studies}

Sixty-six markers (from the 70 in total) were successfully genotyped across these loci. One marker in LRRTMI (rs34285492) and three in LRRTM3 (rs1925574, rs1925575, rs6480244) failed and were removed from the analysis. For the remaining markers, genotype and allele frequencies were calculated from cases and parents for each population across the genes under study. Furthermore, two markers - rs2290170 (LRRTMI) and rs12098475 (LRRTM3) - were monomorphic in the populations studied. The SNPs analysed were in Hardy-Weinberg equilibrium in both probands and founders $(P>0.001)$. TDT statistics were performed for all markers in each population to test for association between the four leucine-rich repeat (LRR) genes and ASD, and it was considered reasonable to interpret a $P<0.005$ to be statistically significant (see Materials 


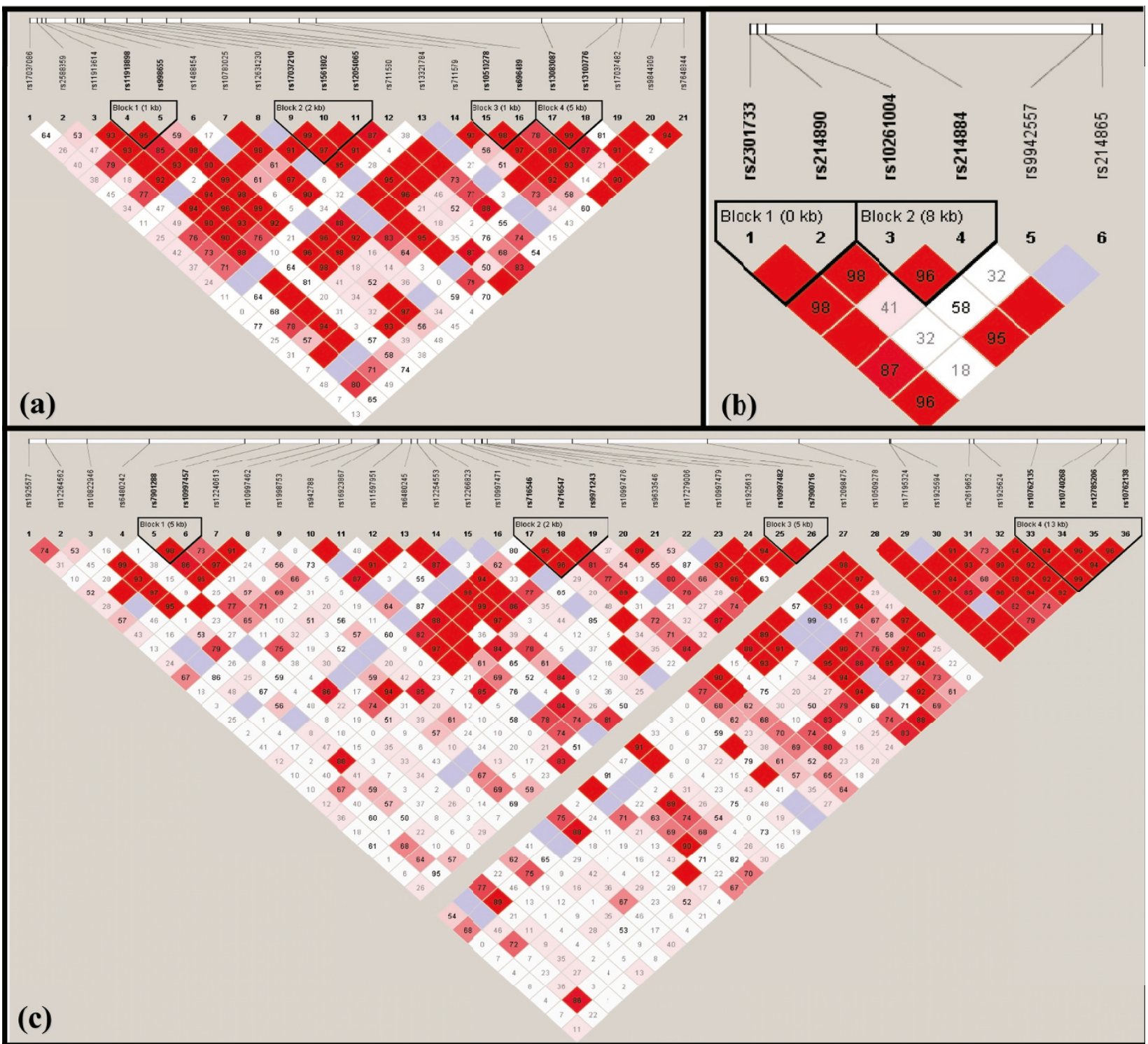

Figure 1 The graphical output from Haploview. The markers tested and the haplotype blocks constructed for (a) LRRN1, (b) LRRN3 and (c) LRRTM3 are included. D' values are indicated (bright red corresponds to D' $=1$, with the colour tending towards white as D' tends towards 0 ).

and Methods). For the IMGSAC families, the analysis was carried out as two groups, since both multiplex and singleton families were present. This follows the suggestions that these two groups have different underlying aetiologies and so could contribute in distinct manners to disease susceptibility and, consequently, should be addressed separately $[59,60]$. A meta-analysis using the entire data was also carried out to weigh and summarize the results obtained with the multiple single TDT tests. The results are shown for each population and for the pooled meta-analysis in Figure 2. Meta-analysis forest plots were constructed for each marker (data not shown) and the six most significant markers from the overall meta-analysis are illustrated in Figure 3. No significant findings were obtained with the LRRTMI gene analysis. One marker (rs1488454) in LRRN1 showed statistically significant transmission disequilibrium, having a preferential transmission of the $\mathrm{C}$ allele to the affected offspring ( $P=0.002$ - Additional File 1 and Figure 2). This significance was present in the singleton cohort within the IMGSAC subgroup, as confirmed in the corresponding forest plot where this population shows an OR deviation from 1 (Figure 3a). For $L R R N 3$, the marker rs10261004 was significant in the Northern Dutch cohort $(P=0.001$ - Additional File 2 and Figure 2). This is shown in the respective forest plot for this subgroup (Figure 3c), with the condition less likely in individuals who carry the $G$ allele (as the OR is below 1). Moreover, the two neighbouring markers were also of nominal significance in the same population. How- 


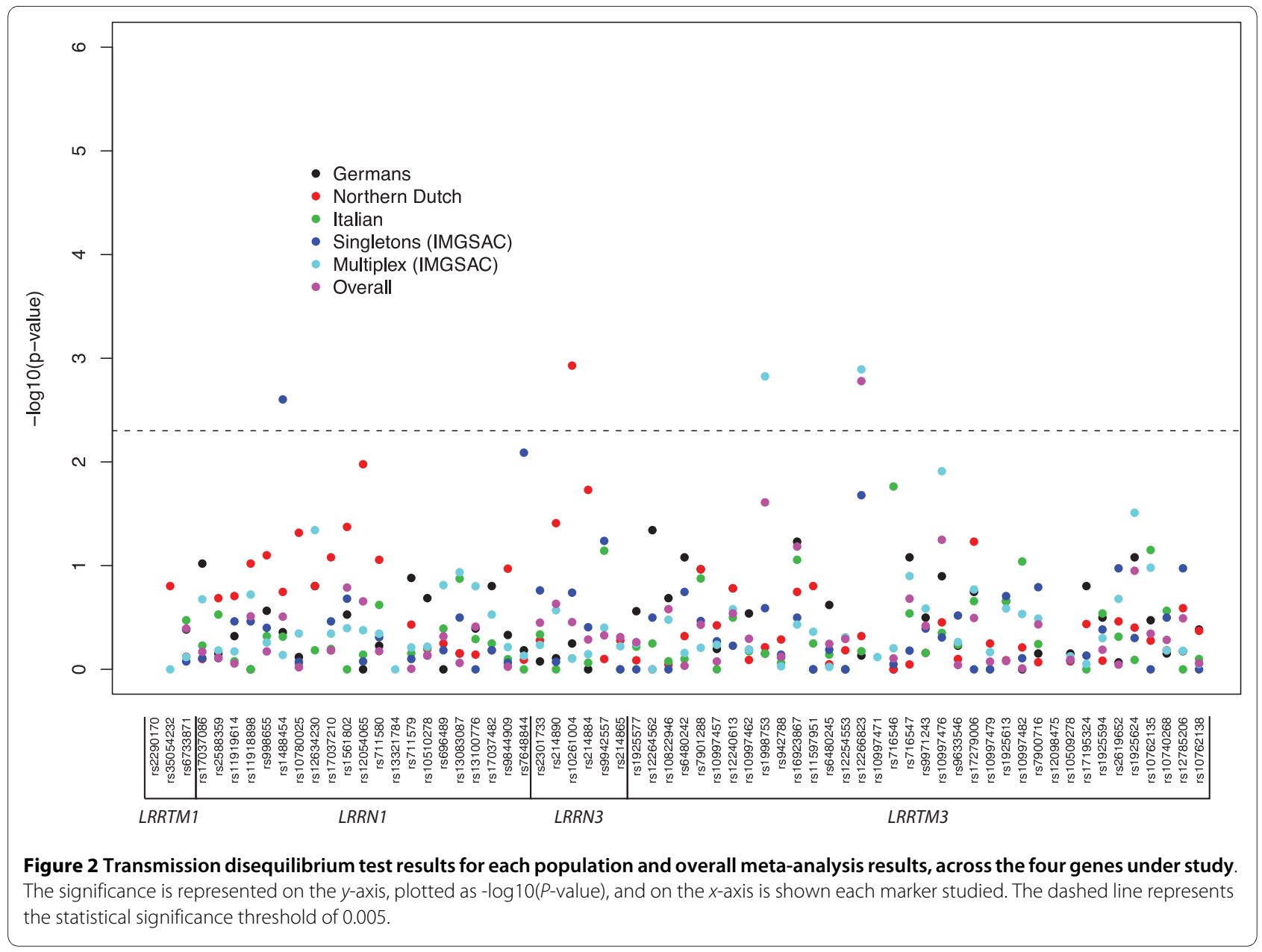

ever, this significance was not present after adjusting for multiple testing corrections. In LRRTM3, two SNPs rs1998753 $(P=0.001)$ and rs12266823 $(P=0.001$ - Additional File 3 and Figure 2) - showed statistically significant transmission disequilibrium. For these markers the significance was being driven especially by the multiplex cohort. However, the pooled meta-analysis was also significant for rs12266823 (Figure 2), showing that other groups were also contributing to the association in the same direction. Furthermore, the respective forest plots (Figure 3d-e) show that the $\mathrm{G}$ allele for rs1998753 confers an increased risk for ASD, while the A allele for rs 12266823 confers a decreased risk. Additionally, rs10997476 had nominal significance, especially in the multiplex samples (Figure 3f), but the significance did not remain after we adjusted for multiple testing. The empirical $P$-values for all TDTs performed are reported in Additional Files 1 to 6, and the significant ones are highlighted in bold. Parental transmissions were examined for each marker, but no evidence of parent-of-origin effects was found $(P>0.12)$.

Examination of the LD patterns across $L R R N 1, L R R N 3$ and LRRTM3 loci, using our genotyping data, showed that each gene defined four, two and four LD blocks, respec- tively $\left(\mathrm{r}^{2}>0.8\right.$ and MAF $>0.05$; Figure 1$)$. In contrast, the SNPs tested in LRRTM1 defined no LD blocks. 'The human genome can be parsed objectively into haplotype blocks: sizable regions over which there is little evidence for historical recombination and within which only a few common haplotypes are observed' [61], which I will call LD blocks. 'If haplotype blocks represent regions inherited without substantial recombination in the ancestors of the current population, then a biological basis for defining haplotype blocks is to examine patterns of recombination across each region. The history of recombination between a pair of SNPs can be estimated with the use of the normalized measure of allelic association, D' '[61]. 'We define pairs to be in "strong LD" if the one-sided upper 95\% confidence bound on $\mathrm{D}^{\prime}$ is $>0.98$ (that is, consistent with no historical recombination) and the lower bound is above 0.7' [61]. Haplotype analysis was performed in order to further assess the transmission disequilibrium within the LD blocks, as haplotypes can sometimes offer more power to detect association compared to single SNPs. Transmission of haplotypes, including all markers within each block, was tested using Transmit [56], along with the multi-marker haplotype com- 


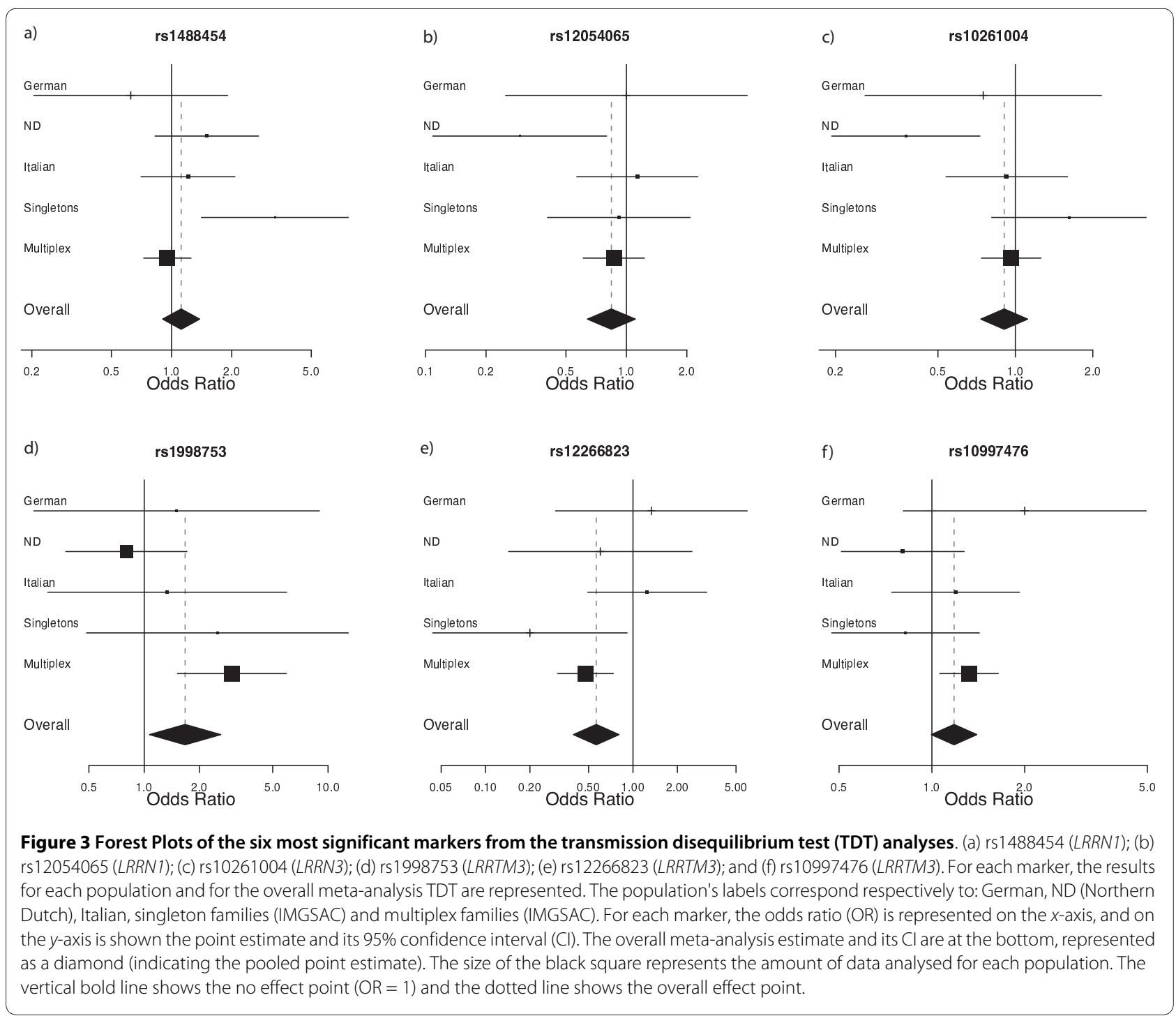

binations from the Tagger output (since the haplotype tagging SNPs were chosen using aggressive tagging). In the overall population, only one significant haplotype specific result was obtained, for a Tagger multi-marker haplotype within LRRTM3 (Table 1). This haplotype contains marker rs12266823 that showed high significance in the single locus association test. Additionally, the two markers in intron 2 (rs6480245 and rs12266823) that comprise this haplotype are in high $\mathrm{LD}$ with each other $\left(\mathrm{D}^{\prime}=87\right.$ - Figure 1c). However, for haplotype GA $(P=0.0005$ - Table 1) the significance of the haplotype was increased compared to the single marker, suggesting that this specific haplotype could potentially increase susceptibility to ASD. Two threemarker haplotypes (rs716546-rs716547-rs9971243) were also over-transmitted to the affected offspring, revealing a possible transmission distortion in LD block 2. However, the significance was above the 0.005 significance threshold established previously and none of the markers that make the haplotypes are in high LD with the significant markers from the single locus TDT test. The same analysis was carried out for separately each gene across the five subgroups of samples and only the haplotype specific $P$-values approaching or below the nominal significance threshold of $P<0.05$ are shown (Table 2). No significant results were obtained with the German and Italian populations or with LRRTM1. Taking each population into account, although some results reach nominal significance for LRRN1 and LRRTM3, they were all above the 0.005 significance threshold previously established. However, for the Northern Dutch population, LRRN3 showed a transmission distortion in LD block 2 with the two-marker (rs10261004 and rs214884) haplotypes GC ( $P=0.005$ - Table 2$)$ and TT ( $P=$ 0.004 - Table 2). However, these haplotypes both contain rs10261004 which, alone, was significant and is most probably driving the association in this case, as the significance was not increased compared to the single locus result. 
Table 1: Haplotype transmission disequilibrium results in the overall population across leucine-rich repeat transmembrane neuronal (LRRTM3).

\begin{tabular}{|c|c|c|c|c|c|c|}
\hline LD block/Tagb & Haplotypea & TR & NT & OR & $\mathbf{C l}$ & P-value \\
\hline Block 2 (rs716546-rs716547-rs9971243) & $\mathrm{CCT}$ & 75 & 52 & 1.44 & $(1.01,2.05)$ & 0.0505 \\
\hline Block 2 (rs716546-rs716547-rs9971243) & CTC & 2 & 10 & 0.20 & $(0.04,0.91)$ & 0.0386 \\
\hline rs6480245, rs12266823b & GA & 44 & 84 & 0.52 & $(0.36,0.75)$ & 0.0005 \\
\hline rs6480245, rs12266823b & $\mathrm{GC}$ & 242 & 186 & 1.30 & $(1.07,1.58)$ & 0.0078 \\
\hline
\end{tabular}

\section{Case-control study}

A case-control study was conducted in parallel, testing probands with ASD against unselected controls, using allele and genotype data from the same 66 SNPs genotyped across the four LRR genes. Minor allele frequencies from controls and cases for each population across the genes under study were calculated and the SNPs were in HardyWeinberg equilibrium in both $(P>0.001)$. Case-control analysis was carried out using logistic regression in probands of each population against the 295 ECACC controls. Results for the allelic tests of association applied to each sample cohort and for the overall meta-analysis are shown in Figure 4 and, again, $P<0.005$ were considered significant. In order to complement and further describe the latter, the most significant results for the genotypic tests of association performed are shown in Table 3. The allelic case control analysis highlighted nine SNPs in total. One marker in LRRN3 (rs10261004) and one in LRRTM3 (rs1998753) were again significant, confirming the results of the single locus TDT study. For rs10261004 the association was detected in the Northern Dutch cohort (consistent with earlier results) and tests of association indicated a decreased risk for the $\mathrm{G}$ allele compared with the $\mathrm{T}$ (G versus T: $P=0.001$; additive $\mathrm{G}: P<0.003)$. The $\mathrm{rs} 1998753$ association is being driven by the Northern Dutch cohort (A versus $\mathrm{G}: P<0.00001$; AG versus GG/AA: $P<0.00001)$, with the other cohorts all having non-significant ORs less than 1 (A versus G: $P=0.21$; AG versus GG: $P=0.48$ ). Across all populations there were no 'AA' genotypes for rs1998753 and the minor allele frequencies were low (A allele: $<5 \%$ ), except in the Northern Dutch cohort (A allele: MAF 0.234), consistent with family-based frequencies. Additionally, there were seven new significant results $(P<$ 0.005) located in LRRTM3 (rs17279006, rs1925613, rs10997482, rs1925594, rs2619652, rs10740268 and rs12785206; Figure 4). The first three polymorphisms (rs17279006, rs1925613, rs10997482) were found to be significant in the overall meta-analysis. The overall results of association tests were: rs17279006 (G versus A: $P<$ 0.002; additive G: $P<0.003$ ), rs 1925613 (C versus A: $P<$ 0.00006 ; additive $\mathrm{C}: P<0.00008$ ) and $\mathrm{rs} 10997482$ (G versus A: $P<0.000006$; additive G: $P<0.00001)$. The markers rs1925613 and rs 10997482 were most significant in the singleton cohort (rs1925613, C versus A, $P<0.0006$; additive $\mathrm{C}, P<0.0009$; and $\mathrm{rs} 10997482$, $\mathrm{G}$ versus $\mathrm{A}, P=$ 0.0004 ; additive A: $P<0.0007)$. For rs 1925594, there was a trend towards increased risk for the $\mathrm{C}$ allele compared with the $\mathrm{T}$ in the Italian population and in the meta-analysis. However, the number of allele counts is too low to reach a confident conclusion about this result. The marker rs2619652 was significant in the overall meta-analysis and, in particular, in the singleton cohort, presenting an increased risk for the $\mathrm{C}$ allele compared with the T $(P<$ 0.0007; additive T: $P<0.002$ ). The marker rs 10740268 was only significant in the overall meta-analysis, showing an increased risk for the $\mathrm{C}$ allele compared with $\mathrm{T}(P<$ 0.00002; additive $\mathrm{C}: P<0.00003)$. Lastly, the marker rs12785206 was, again, more significant in the singleton cohort, having a decreased risk of the $\mathrm{C}$ allele compared with the T $(P<0.0007$; $\mathrm{CC} / \mathrm{CT}$ versus TT: $P=0.0004)$. Overall, the case-control provides increasing evidence of significant association between LRRTM3 and ASD susceptibility, not only by confirming the association with rs1998753 but also through the new significant results within the gene.

\section{Discussion}

Recently, there has been increasing attention towards the LRR group of transmembrane proteins and their relationship with neurological complex disorders. The LRRs analysed here are thought to be synaptic organizing molecules and have been implicated in brain development, which is 
Table 2: Haplotype transmission disequilibrium results per population across the four genes studied.

\begin{tabular}{|c|c|c|c|c|c|c|c|c|c|c|c|c|c|c|}
\hline \multirow[t]{2}{*}{ Gene } & \multirow[t]{2}{*}{ LD block/Tagb } & \multirow[t]{2}{*}{ Hapa } & \multicolumn{4}{|c|}{ IMGSAC (Multiplex families) } & \multicolumn{4}{|c|}{ IMGSAC (Singleton families) } & \multicolumn{4}{|c|}{ Northern Dutch } \\
\hline & & & TR & NT & $\mathrm{OR} / \mathrm{Cl}$ & $\begin{array}{l}P \text { - } \\
\text { value }\end{array}$ & TR & NT & $\mathrm{OR} / \mathrm{Cl}$ & $\begin{array}{l}\text { P- } \\
\text { value }\end{array}$ & TR & NT & $\mathrm{OR} / \mathrm{CI}$ & $\begin{array}{l}\text { P- } \\
\text { value }\end{array}$ \\
\hline LRRN3 & $\begin{array}{l}\text { Block } 2 \\
\text { (rs10261004- } \\
\text { rs214884) }\end{array}$ & GC & & & & & & & & & 9 & 26 & $\begin{array}{l}0.35 \\
(0.16,0.74)\end{array}$ & 0.005 \\
\hline LRRN3 & $\begin{array}{l}\text { Block } 2 \\
\text { (rs10261004- } \\
\text { rs214884) }\end{array}$ & $\pi$ & & & & & & & & & 44 & 20 & $\begin{array}{l}2.20 \\
(1.30,3.73)\end{array}$ & 0.004 \\
\hline LRRN1 & $\begin{array}{l}\text { Block } 3 \\
\text { (rs10510278- } \\
\text { rs696489) }\end{array}$ & $A C$ & 98 & 70 & $\begin{array}{l}1.40 \\
(1.03,1.90)\end{array}$ & 0.037 & & & & & & & & \\
\hline LRRN1 & $\begin{array}{l}\text { Block } 3 \\
\text { (rs10510278- } \\
\text { rs696489) }\end{array}$ & $\pi$ & 61 & 85 & $\begin{array}{l}0.72 \\
(0.52,1.00)\end{array}$ & 0.057 & & & & & & & & \\
\hline LRRN1 & $\begin{array}{l}\text { rs10780025, } \\
\text { rs13100776 }\end{array}$ & AT & 18 & 37 & $\begin{array}{l}0.49 \\
(0.28,0.85)\end{array}$ & 0.014 & & & & & & & & \\
\hline LRRTM3 & $\begin{array}{l}\text { rs1925613, } \\
\text { rs10762138b }\end{array}$ & $\mathrm{CT}$ & 8 & 20 & $\begin{array}{l}0.40 \\
(0.18,0.91)\end{array}$ & 0.036 & & & & & & & & \\
\hline LRRTM3 & $\begin{array}{l}\text { rs1925613, } \\
\text { rs1925624b }\end{array}$ & AT & 139 & 102 & $\begin{array}{l}1.36 \\
(1.06,1.76)\end{array}$ & 0.020 & & & & & & & & \\
\hline LRRTM3 & $\begin{array}{l}\text { rs2619652, } \\
\text { rs12785206 }\end{array}$ & CC & & & & & 18 & 7 & $\begin{array}{l}2.57 \\
(1.07,6.16)\end{array}$ & 0.043 & & & & \\
\hline LRRTM3 & $\begin{array}{l}\text { rs2619652, } \\
\text { rs12785206b }\end{array}$ & $\pi$ & & & & & 9 & 22 & $\begin{array}{l}0.41 \\
(0.19,0.89)\end{array}$ & 0.029 & & & & \\
\hline LRRTM3 & $\begin{array}{l}\text { rs1925613, } \\
\text { rs12785206b }\end{array}$ & $\mathrm{CT}$ & & & & & 8 & 21 & $\begin{array}{l}0.38 \\
(0.17,0.86)\end{array}$ & 0.024 & & & & \\
\hline
\end{tabular}

The analysis was performed within each linkage disequilibrium (LD) block for each gene and for the haplotype combinations from Haploview (selected by Tagger). Only haplotypesa approaching or below the nominal significance threshold of $\mathrm{P}<0.05$ are shown

aHaplotypes only reported if there are more than 10 informative transmissions in total.

bHaplotype combinations selected by Tagger.

$\mathrm{Cl}$, confidence interval; Hap, Haplotype; NT, non-transmitted; OR, odds ratio; SNP, single nucleotide polymorphism; TR, transmitted. 


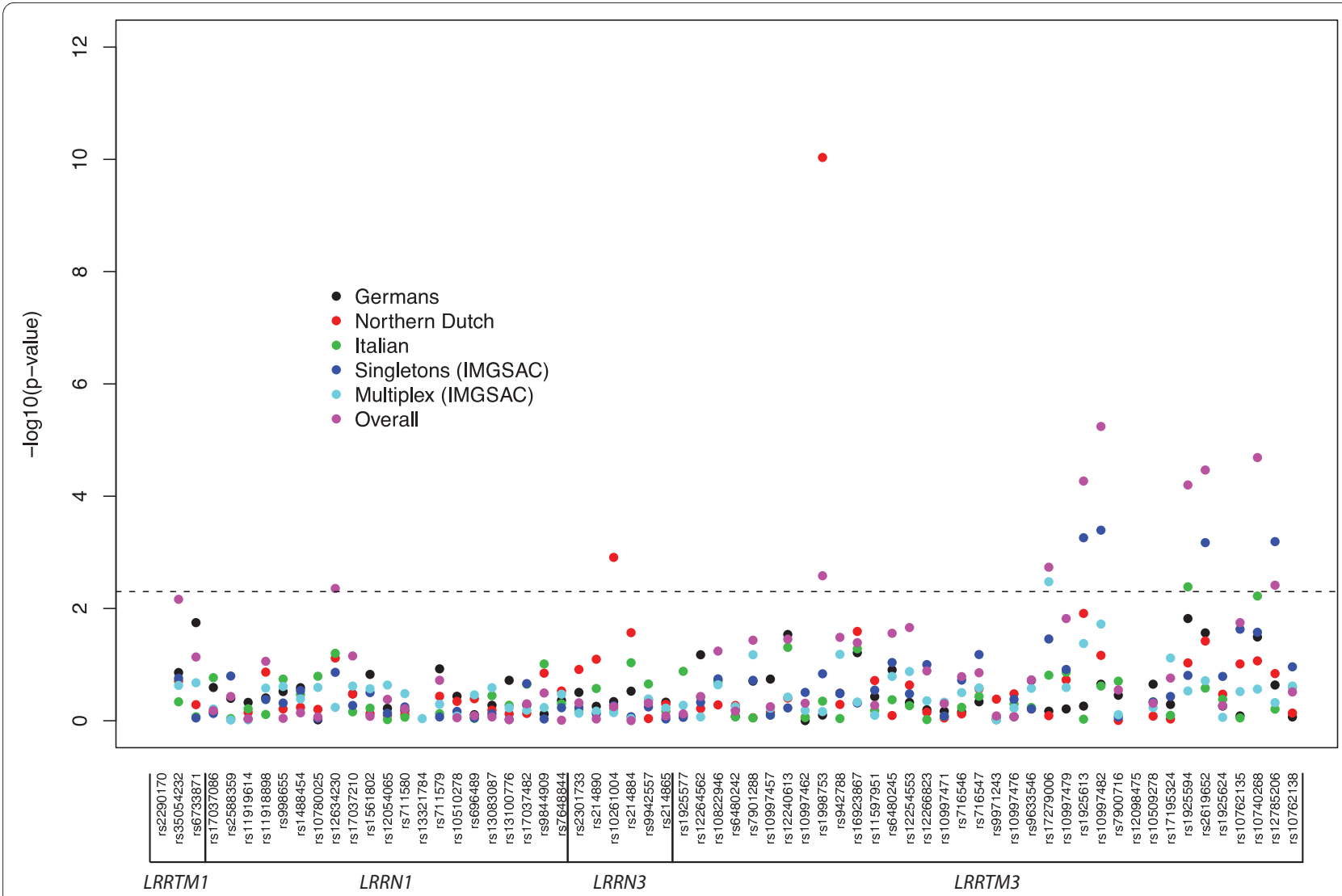

Figure 4 Case-control allele-based tests of association performed for each population and for the overall meta-analysis. The significance is represented on the $y$-axis, plotted as $-\log _{10}(P$-value) and on the $x$-axis is shown each marker studied. The dashed line represents the statistical significance threshold of 0.005 . 'Overall' represents the pooled meta-analysis performed.

often impaired in autistic individuals $[8,14,18,19,21,32]$. In the current study, we hypothesized that common variants in the leucine motifs gene class could possibly be involved in ASD pathogenesis. Specifically, LRRTM1, LRRTM3, $L R R N 1$ and $L R R N 3$ were examined as candidate genes in four different populations of European ancestry by carrying out parallel family-based and case-control studies.

$L R R N 1$ showed only one significant result with the marker rs1488454, showing that its $\mathrm{C}$ allele is increasing the susceptibility to ASDs in the singleton cohort. However, this result was not confirmed by the case-control analysis which points to a weaker evidence for a role in susceptibility.

The family based study showed that rs10261004 within LRRN3 is strongly associated with ASD risk in the Northern Dutch cohort and that its $\mathrm{G}$ allele is protective for susceptibility to the disorder. The haplotype analysis also showed evidence of significance with two haplotypes within LD block 2. Moreover, the case-control analysis confirmed the evidence of an association with this marker, showing a decreased risk for the $\mathrm{G}$ allele and for the $\mathrm{GG}$ / GT genotypes (compared to the T allele and TT genotype, respectively). This is the most consistent result that we have found, as the marker is significant in all the tests performed in the Northern Dutch cohort and, therefore, it could be a population specific susceptibility. The non-association reported for this gene in the Collaborative Linkage Study of Autism dataset by Hutcheson et al. [45] could be explained by several factors: differences in sample ascertainment, family numbers and the hypothesis that one of the results is a false positive. In effect, they tested 30 nuclear families, which could have limited their ability to detect the association signal that we are observing in our cohort. In addition, none of the four markers tested in their study were in high LD with rs 10261004.

LRRTM3 was the gene that showed most evidence of association in the populations that we studied. In particular, rs 1998753 was the most consistent significant marker within this gene, showing that its $\mathrm{G}$ allele increases the risk for ASD, especially in the multiplex cohort (but was also significant in the pooled meta-analysis). Although this effect was evident in all case-control cohorts except the Northern Dutch, it did not reach a significant level of statistical evidence. In fact, in the Northern Dutch case-control 
Table 3: Case-control genotype-based test results.

\begin{tabular}{|c|c|c|c|c|c|}
\hline SNP & Population & Model & OR & $\mathbf{C l}$ & P-value \\
\hline rs10261004 & Northern Dutch & Additive G & 0.44 & $(0.26,0.75)$ & $3.00 \mathrm{E}-03$ \\
\hline rs10261004 & Northern Dutch & TT versus GG/GT & 2.42 & $(1.33,4.41)$ & $4.00 \mathrm{E}-03$ \\
\hline rs1998753 & Northern Dutch & Additive G & 0.10 & $(0.05,0.20)$ & $5.68 \mathrm{E}-12$ \\
\hline rs1998753 & Northern Dutch & $A G$ versus $G G / A A$ & 9.64 & $(5.06,18.38)$ & $5.68 \mathrm{E}-12$ \\
\hline rs17279006 & Overall & Additive G & 0.62 & $(0.45,0.84)$ & $2.22 \mathrm{E}-03$ \\
\hline rs17279006 & Overall & $A A$ versus $G G / A G$ & 1.65 & $(1.19,2.29)$ & $2.59 \mathrm{E}-03$ \\
\hline rs17279006 & Multiplex (IMGSAC) & $A A$ versus $G G / A G$ & 2.14 & $(1.28,3.59)$ & $3.96 \mathrm{E}-03$ \\
\hline rs17279006 & Multiplex (IMGSAC) & Additive G & 0.49 & $(0.30,0.79)$ & 4.00E-03 \\
\hline rs1925613 & Overall & $C C$ versus $\mathrm{AA} / \mathrm{AC}$ & 1.81 & $(1.37,2.39)$ & 2.97E-05 \\
\hline rs1925613 & Overall & Additive C & 1.35 & $(1.16,1.57)$ & $7.82 \mathrm{E}-05$ \\
\hline rs1925613 & Singleton (IMGSAC) & $C C$ versus $A A / A C$ & 3.01 & $(1.66,5.47)$ & $2.81 \mathrm{E}-04$ \\
\hline rs1925613 & Singleton (IMGSAC) & Additive C & 1.80 & $(1.27,2.54)$ & 8.97E-04 \\
\hline rs10997482 & Overall & Additive G & 1.38 & $(1.20,1.60)$ & $9.81 \mathrm{E}-06$ \\
\hline rs10997482 & Overall & GG versus $A A / A G$ & 1.60 & $(1.27,2.00)$ & 4.63E-05 \\
\hline rs10997482 & Singleton (IMGSAC) & Additive A & 0.54 & $(0.38,0.77)$ & $6.85 \mathrm{E}-04$ \\
\hline rs10997482 & Singleton (IMGSAC) & GG versus $A A / A G$ & 2.41 & $(1.45,4.03)$ & $7.45 \mathrm{E}-04$ \\
\hline rs2619652 & Overall & Additive T & 0.76 & $(0.67,0.88)$ & $1.57 \mathrm{E}-04$ \\
\hline rs2619652 & Overall & $\mathrm{TT}$ versus $\mathrm{CC} / \mathrm{CT}$ & 0.63 & $(0.49,0.81)$ & $2.71 \mathrm{E}-04$ \\
\hline rs2619652 & Singleton (IMGSAC) & Additive T & 0.58 & $(0.41,0.82)$ & $1.95 \mathrm{E}-03$ \\
\hline rs2619652 & Singleton (IMGSAC) & $\Pi \pi$ versus $\mathrm{CC} / \mathrm{CT}$ & 0.34 & $(0.17,0.69)$ & $2.56 \mathrm{E}-03$ \\
\hline rs10740268 & Overall & $\mathrm{TT}$ versus $\mathrm{CC} / \mathrm{CT}$ & 0.51 & $(0.38,0.70)$ & $2.16 \mathrm{E}-05$ \\
\hline rs10740268 & Overall & Additive $C$ & 1.84 & $(1.38,2.45)$ & $3.48 \mathrm{E}-05$ \\
\hline rs12785206 & Overall & $\mathrm{TT}$ versus $\mathrm{CC} / \mathrm{CT}$ & 1.49 & $(1.20,1.86)$ & $3.96 \mathrm{E}-04$ \\
\hline rs12785206 & Singleton (IMGSAC) & $\mathrm{CC} / \mathrm{CT}$ versus $\mathrm{TT}$ & 0.37 & $(0.22,0.65)$ & 4.20E-04 \\
\hline rs12785206 & Singleton (IMGSAC) & Additive C & 0.48 & $(0.31,0.74)$ & $1.00 \mathrm{E}-03$ \\
\hline
\end{tabular}

Only the most significant results are shown $(P<0.005)$. SNP, single nucleotide polymorphism; $\mathrm{OR}$, odds ratio; $\mathrm{Cl}$, confidence interval.

cohort, which is a more isolated population than the others, there is strong evidence that the A allele increases the risk for ASD and that there is a non-significant over-transmission of the A allele to cases in the TDT. Consequently, for the case-control, although the Northern Dutch result could be a false positive, it biases the overall results. The statistical power of the case-control analysis is hindered by the small sample size of our control cohort, by sampling cases from a population possibly different to the others and by false positives which were possibly due to the population structure. In contrast, the family-based study is robust to population stratification. So, although the case-control result can be taken as a verification of the positive evidence of association with this marker, this result warrants further confirmation that could be achieved by another replication study or by genotyping a larger control group for this marker, preferably including a set of controls from the Northern Dutch population. In addition to rs1998753, rs12266823 was also significant, with the A allele being protective against ASD risk in the multiplex cohort and in the pooled meta-analysis of the TDT. However, this result was not confirmed by the case-control analysis. Nevertheless, new associations within LRRTM3 were found in the case-control study with the markers rs17279006, rs1925613, rs10997482, rs2619652, rs10740268 and rs12785206. All of these were significant in the overall analysis. For rs17279006 the G allele and GG(/GT) genotypes were protective against the disorder, whereas for the rs1925613 C allele, and CC(/CA) and rs10997482 G allele and $\mathrm{GG} / / \mathrm{GA})$ genotypes, the risk of ASD was increased (the last two markers being most significant in the singleton cohort in the genotypic test). For rs 10740268 the $\mathrm{C}$ allele 
and $\mathrm{CC}(/ \mathrm{CT})$ genotypes there was an increasing risk to ASDs in the overall meta-analysis. Moreover, rs2619652 and rs12785206 were both significant in the singleton cohort; the first presenting an increased risk for the $\mathrm{C}$ allele and $\mathrm{CC}(/ \mathrm{CT})$ genotypes and the second having a decreased risk for the $\mathrm{C}$ allele and $\mathrm{CC} / \mathrm{CT}$ genotypes. Therefore, overall there is growing evidence that LRRTM3 may play a role in ASD susceptibility.

Interestingly, significant results from the TDT analysis were only replicated in the case-control study for two markers. However, seven new significant markers appeared in the latter that were not previously identified by the TDT. Several explanations can be proposed for this occurrence but the most evident is the use of different analytical approaches. Both TDT and case-control studies use different methods to access association, and while the TDT is more robust to population stratification, the case-control has in general more power to detect association in studies such as ours. We cannot exclude the possibility that subtle population structure (detected using many hundreds or thousands of markers) may lead to false positive results in the case-control analyses above. We suggest further that there should be an assessment of the case-control specific association markers in a larger number of controls and, if possible, a correction for population structure or other confounding effects using many more markers. The two analyses presented complement each other and reflect the complex heterogeneity of the disorder spectrum, pointing once more to the difficulty of studying ASDs. Additionally, different markers within LRRTM3 were differently associated to multiplex and singleton families, supporting the theory that we are looking at genetically different groups within the same population that have different patterns of ASD traits $[59,60]$.

As both associated genes, LRRTM3 and LRRN3, are nested, they are possibly transcriptionally co-regulated with the genes that contain them (CTNNA3 and IMMP2L, respectively) [8]. Unknown regulatory mechanisms could be present in these regions altering gene expression or even splicing patterns which, in turn, could contribute to ASD susceptibility. Moreover, Wang et al. found an association with autism with one intronic marker (rs9651325) in CTNNA3, which is located 3 ' to LRRTM3, a region that was not covered by our study [13]. Both these LRR genes warrant further investigation as they are highly expressed in the brain, particularly the cerebellum, $[8,14]$ (a characteristically impaired region in autistic individuals $[62,63])$, involved in central nervous system development and regeneration $[8,14,27,28,31]$, and there is accumulating evidence implicating these genic regions in ASD susceptibility $[13,44]$.

\section{Conclusions}

Taken together, there is converging evidence that common genetic variants in LRRTM3 and LRRN3 confer susceptibility to ASD and further study of these genes and their function will provide valuable insights into their role in ASD pathogenesis. In summary, this is one of the first studies to show results of an association between more than one leucine-rich repeat gene and ASD susceptibility in populations of European ancestry.

\section{List of Abbreviations}

ASDs: autism spectrum disorders; ADI-R: autism diagnostic interview-revised; ADOS: autism diagnostic observation schedule; CI: confidence interval; CNS: central nervous system; CTNNA2: $\alpha 2$-cateni; CTNNA3: $\alpha$ T-catenin; ECACC: European Collection of Cell Cultures; IMGSAC: The International Molecular Genetic Study of Autism Consortium; IMMP2L: inner mitochondrial membrane peptidase-like; LD: linkage disequilibrium; LRR: leucine-rich repeat; LRRN: leucine rich repeat neuronal; LRRTM: leucine rich repeat transmembrane neuronal; MAF: minor allele frequency; mRNA: messenger RNA; OR: odds ratio; SNP: single nucleotide polymorphism; TDT: transmission disequilibrium test.

\section{Additional material}

Additional file 1 TDT results for the single nucleotide polymorphisms genotyped across LRRTM1, LRRN1, LRRN3 and LRRTM3 genes in the singleton families of the International Molecular Genetic Study of Autism Consortium population.

Additional file $\mathbf{2}$ TDT results for the single nucleotide polymorphisms genotyped across LRRTM1, LRRN1, LRRN3 and LRRTM3 genes in the Northern Dutch population.

Additional file 3 TDT results for the single nucleotide polymorphisms genotyped across LRRTM1, LRRN1, LRRN3 and LRRTM3 genes in the multiplex families of the International Molecular Genetic Study of Autism Consortium population.

Additional file 4 TDT results for the single nucleotide polymorphisms genotyped across LRRTM1, LRRN1, LRRN3 and LRRTM3 genes in the Italian population.

Additional file 5 TDT results for the single nucleotide polymorphisms genotyped across LRRTM1, LRRN1, LRRN3 and LRRTM3 genes in the German population.

Additional file 6 TDT Meta-analysis results for the single nucleotide polymorphisms genotyped across LRRTM1, LRRN1, LRRN3 and LRRTM3 genes.

Competing interests

The authors declare that they have no competing interests.

\section{Authors' contributions}

IS, TGC and APM participated in the design of the study. IS performed the molecular genetic study (acquisition, statistical analysis and interpretation of the data) and carried out the writing of the manuscript. TGC performed the statistical analysis as well as the interpretation of the data. $\mathrm{RH}$ and ATP both helped to perform the DNA preparation, primer selection and interpretation of the data, as well critically revising the manuscript for intellectual content. EM, RBM, AJB, AB, SMK and FP performed the clinical assessment of patients and DNA sample collection of the Northern Dutch, IMGSAC, Italian and German populations, as well as revising for intellectual content. APM supervised the 
molecular genetic experiments and critically revised the manuscript for intellectual content. All authors read and approved the final manuscript.

\section{Acknowledgements}

We sincerely thank all the families who have participated in the study and the professionals who made this study possible. We would like to thank Chris Allan at the WTCHG core genomics facility for technical support (Sequenom genotyping). We gratefully thank Nuala Sykes, Kirsty Wing, Clotilde Leveque and Susana Campino for their helpful discussions and critical comments. This work was supported by the Nancy Lurie Marks Family Foundation; the Simons Foundation; the EC 6th FP AUTISM MOLGEN [grant No. LSHM-CT-2005-512158]; the Wellcome Trust [grant No. 076566/Z/05/Z]; and the Fundação para a Ciência e Tecnologia (FCT-Portugal). IS is funded by FCT-Portugal (SFRH/BD/21405/2005). TGC is funded by the Bill and Melinda Gates Foundation through the National Institutes of Health [grant No. 566], the Wellcome Trust [grant No. 077383/Z/ 05/Z] and the Medical Research Council UK [grant No. G0600230]. RH and AB are funded by the EC 6th FP AUTISM MOLGEN [grant No. LSHM-CT-2005512158]; ATP is funded by the Nancy Lurie Marks Family Foundation and the Simons Foundation; EM and RBM are funded through the EC 6th FP AUTISM MOLGEN [grant No. LSHM-CT-2005-512158], the Accare (University Center Child and Adolescent Psychiatry) and through the Netherlands Organization for Scientific Research (NWO). SMK and FP are funded by the Deutsche Forschungsgemeinschaft (German Research Foundation) grant No. PO 255/17-4; APM is funded by the Nancy Lurie Marks Family Foundation and the Simons Foundation.

International Molecular Genetic Study of Autism Consortium (IMGSAC): http:// www.well.ox.ac.uk/monaco/autism/IMGSAC.shtm/

\section{Author Details}

'Wellcome Trust Centre for Human Genetics, University of Oxford, Oxford OX3 7BN, UK, 2Departments of Epidemiology and Public Health, and Infectious and Tropical Diseases, London School of Hygiene and Tropical Medicine, London WC1E 7HT, UK, ${ }^{3}$ Department of Psychiatry, Child and Adolescent Psychiatry, University Medical Center Groningen, PO Box 660, 9700 AR Groningen, the Netherlands, 4University Department of Psychiatry, Warneford Hospital, Oxford, UK, 5 Stella Maris Clinical Research Institute for Child and Adolescent Neuropsychiatry, Calambrone (Pisa), Italy, 6 Division of Molecular Genome Analysis, German Cancer Research Center, Heidelberg, Germany and ${ }^{7}$ Department of Child and Adolescent Psychiatry, Johann Wolfgang GoetheUniversity, Frankfurt/Main, Germany

Received: 2 September 2009 Accepted: 25 March 2010

Published: 25 March 2010

\section{References}

1. Lord C, Cook EH, Leventhal BL, Amaral DG: Autism spectrum disorders. Neuron 2000, 28:355-363.

2. Bailey A, Le Couteur A, Gottesman I, Bolton P, Simonoff E, Yuzda E, Rutter M: Autism as a strongly genetic disorder: evidence from a British twin study. Psychol Med 1995, 25:63-77.

3. Santangelo SL, Tsatsanis K: What is known about autism: genes, brain, and behavior. Am J Pharmacogenomics 2005, 5:71-92.

4. Volkmar FR, Paul R, Klin A, Cohen D: Handbook of Autism and Pervasive Developmental Disorders. New Jersey: John Wiley \& Sons; 2005.

5. Kobe B, Kajava AV: The leucine-rich repeat as a protein recognition motif. Curr Opin Struct Biol 2001, 11:725-732.

6. Mutai H, Toyoshima Y, Sun W, Hattori N, Tanaka S, Shiota K: PAL31, a novel nuclear protein, expressed in the developing brain. Biochem Biophys Res Commun 2000, 274:427-433.

7. Linhoff MW, Harton JA, Cressman DE, Martin BK, Ting JP: Two distinct domains within CIITA mediate self-association: involvement of the GTP-binding and leucine-rich repeat domains. Mol Cell Biol 2001, 21:3001-3011.

8. Lauren J, Airaksinen MS, Saarma M, Timmusk T: A novel gene family encoding leucine-rich repeat transmembrane proteins differentially expressed in the nervous system. Genomics 2003, 81:411-421.

9. Fournier AE, GrandPre T, Strittmatter SM: Identification of a receptor mediating Nogo-66 inhibition of axonal regeneration. Nature 2001, 409:341-346.
10. Wu W, Wong K, Chen J, Jiang Z, Dupuis S, Wu JY, Rao Y: Directional guidance of neuronal migration in the olfactory system by the protein Slit. Nature 1999, 400:331-336.

11. Morante-Redolat JM, Gorostidi-Pagola A, Piquer-Sirerol S, Saenz A, Poza JJ, Galan J, Gesk S, Sarafidou T, Mautner VF, Binelli S, et al.: Mutations in the LGI1/Epitempin gene on 10q24 cause autosomal dominant lateral temporal epilepsy. Hum Mol Genet 2002, 11:1119-1128.

12. Singleton AB: Altered alpha-synuclein homeostasis causing Parkinson's disease: the potential roles of dardarin. Trends Neurosci 2005, 28:416-421.

13. Wang K, Zhang H, Ma D, Bucan M, Glessner JT, Abrahams BS, Salyakina D, Imielinski M, Bradfield JP, Sleiman PM, et al.: Common genetic variants on 5p14.1 associate with autism spectrum disorders. Nature 2009, 459:528-533.

14. Haines BP, Gupta R, Jones CM, Summerbell D, Rigby PW: The NLRR gene family and mouse development: Modified differential display PCR identifies NLRR-1 as a gene expressed in early somitic myoblasts. Dev Biol 2005, 281:145-159.

15. Nagafuchi A: Molecular architecture of adherens junctions. Curr Opin Cell Biol 2001, 13:600-603.

16. Morrow EM, Yoo SY, Flavell SW, Kim TK, Lin Y, Hill RS, Mukaddes NM, Balkhy S, Gascon G, Hashmi A, et al.: Identifying autism loci and genes by tracing recent shared ancestry. Science 2008, 321:218-223.

17. Bhalla K, Luo Y, Buchan T, Beachem MA, Guzauskas GF, Ladd S, Bratcher SJ, Schroer RJ, Balsamo J, DuPont BR, et al.: Alterations in $\mathrm{CDH} 15$ and KIRREL3 in patients with mild to severe intellectual disability. Am J Hum Genet 2008, 83:703-713.

18. Haines BP, Rigby PW: Developmentally regulated expression of the LRRTM gene family during mid-gestation mouse embryogenesis. Gene Expr Patterns 2007, 7:23-29.

19. Linhoff MW, Lauren J, Cassidy RM, Dobie FA, Takahashi H, Nygaard HB, Airaksinen MS, Strittmatter SM, Craig AM: An unbiased expression screen for synaptogenic proteins identifies the LRRTM protein family as synaptic organizers. Neuron 2009, 61:734-749.

20. Bourgeron T: Synaptic Plasticity and the Mechanism of Alzheimer's Disease (Genes, Synapses and Autism Spectrum Disorders). Berlin: Springer; 2008.

21. Francks C, Maegawa S, Lauren J, Abrahams BS, Velayos-Baeza A, Medland SE, Colella S, Groszer M, McAuley EZ, Caffrey TM, et al.: LRRTM1 on chromosome $2 \mathrm{p} 12$ is a maternally suppressed gene that is associated paternally with handedness and schizophrenia. Mol Psychiatry 2007 12:1129-1139. 1057

22. Herbert MR, Harris GJ, Adrien KT, Ziegler DA, Makris N, Kennedy DN, Lange NT, Chabris CF, Bakardjiev A, Hodgson J, et al.: Abnormal asymmetry in language association cortex in autism. Ann Neurol 2002, 52:588-596.

23. De Fosse L, Hodge SM, Makris N, Kennedy DN, Caviness VS Jr, McGrath L, Steele S, Ziegler DA, Herbert MR, Frazier JA, et al.: Language-association cortex asymmetry in autism and specific language impairment. Ann Neurol 2004, 56:757-766.

24. Majercak J, Ray WJ, Espeseth A, Simon A, Shi XP, Wolffe C, Getty K, Marine $\mathrm{S}$, Stec E, Ferrer M, et al.: LRRTM3 promotes processing of amyloidprecursor protein by BACE1 and is a positional candidate gene for lateonset Alzheimer's disease. Proc Natl Acad Sci USA 2006, 103:17967-17972

25. Liang X, Martin ER, Schnetz-Boutaud N, Bartlett J, Anderson B, Zuchner S, Gwirtsman H, Schmechel D, Carney R, Gilbert JR, et al.: Effect of heterogeneity on the chromosome 10 risk in late-onset Alzheimer disease. Hum Mutat 2007, 28:1065-1073.

26. Taguchi A, Wanaka A, Mori T, Matsumoto K, Imai Y, Tagaki T, Tohyama M: Molecular cloning of novel leucine-rich repeat proteins and their expression in the developing mouse nervous system. Brain Res Mol Brain Res 1996, 35:31-40.

27. Ishii N, Wanaka A, Tohyama M: Increased expression of NLRR-3 mRNA after cortical brain injury in mouse. Brain Res Mol Brain Res 1996, 40:148-152

28. Bormann P, Roth LW, Andel D, Ackermann M, Reinhard E: zfNLRR, a novel leucine-rich repeat protein is preferentially expressed during regeneration in zebrafish. Mol Cell Neurosci 1999, 13:167-179.

29. Aubert J, Stavridis MP, Tweedie S, O'Reilly M, Vierlinger K, Li M, Ghazal P, Pratt T, Mason JO, Roy D, Smith A: Screening for mammalian neural genes via fluorescence-activated cell sorter purification of neural 
precursors from Sox1-gfp knock-in mice. Proc Natl Acad Sci USA 2003, 100(suppl 1):11836-11841.

30. Fukamachi K, Matsuoka Y, Ohno H, Hamaguchi T, Tsuda H: Neuronal leucine-rich repeat protein-3 amplifies MAPK activation by epidermal growth factor through a carboxyl-terminal region containing endocytosis motifs. J Biol Chem 2002, 277:43549-43552.

31. Chen Y, Aulia S, Li L, Tang BL: AMIGO and friends: an emerging family of brain-enriched, neuronal growth modulating, type I transmembrane proteins with leucine-rich repeats (LRR) and cell adhesion molecule motifs. Brain Res Rev 2006, 51:265-274.

32. Andreae LC, Peukert D, Lumsden A, Gilthorpe JD: Analysis of Lrrn 1 expression and its relationship to neuromeric boundaries during chick neural development. Neural Develop 2007, 2:22.

33. Higgins JJ, Pucilowska J, Lombardi RQ, Rooney JP: Candidate genes for recessive non-syndromic mental retardation on chromosome $3 p$ (MRT2A). Clin Genet 2004, 65:496-500.

34. Davis L, Meyer K, Rudd D, Librant A, Epping E, Sheffield VTW: Novel Copy Number Variants in Children with Autism and Additional Developmental Anomalies. ASHG Philadelphia-asbtract number 1735/W 2008.

35. Fukamachi K, Matsuoka Y, Kitanaka C, Kuchino Y, Tsuda H: Rat neuronal leucine-rich repeat protein-3: cloning and regulation of the gene expression. Biochem Biophys Res Commun 2001, 287:257-263.

36. IMGSAC: A full genome screen for autism with evidence for linkage to a region on chromosome 7q. Hum Mol Genet 1998, 7:571-578.

37. IMGSAC: A genomewide screen for autism: strong evidence for linkage to chromosomes 2q, 7q, and 16p. Am J Hum Genet 2001, 69:570-581.

38. Lamb JA, Barnby G, Bonora E, Sykes N, Bacchelli E, Blasi F, Maestrini E, Broxholme J, Tzenova J, Weeks D, International Molecular Genetic Study of Autism Consortium, et al.: Analysis of IMGSAC autism susceptibility loci: evidence for sex limited and parent of origin specific effects. J Med Genet 2005, 42:132-137.

39. Barrett S, Beck JC, Bernier R, Bisson E, Braun TA, Casavant TL, Childress D, Folstein SE, Garcia M, Gardiner MB, et al.: An autosomal genomic screen for autism. Collaborative linkage study of autism. Am J Med Genet 1999, 88:609-615.

40. Risch N, Spiker D, Lotspeich L, Nouri N, Hinds D, Hallmayer J, Kalaydjieva L, McCague P, Dimiceli S, Pitts T, et al.: A genomic screen of autism: evidence for a multilocus etiology. Am J Hum Genet 1999, 65:493-507.

41. Philippe A, Martinez M, Guilloud-Bataille M, Gillberg C, Rastam M, Sponheim E, Coleman M, Zappella M, Aschauer H, Van Maldergem L, et al.: Genome-wide scan for autism susceptibility genes. Paris Autism Research International Sibpair Study. Hum Mol Genet 1999, 8:805-812.

42. Badner JA, Gershon ES: Regional meta-analysis of published data supports linkage of autism with markers on chromosome $7 . \mathrm{Mol}$ Psychiatry 2002, 7:56-66.

43. Trikalinos TA, Karvouni A, Zintzaras E, Ylisaukko-oja T, Peltonen L, Jarvela I, loannidis JP: A heterogeneity-based genome search meta-analysis for autism-spectrum disorders. Mol Psychiatry 2006, 11:29-36.

44. Maestrini E, Pagnamenta AT, Lamb JA, Bacchelli E, Sykes NH, Sousa I, Toma C, Barnby G, Butler H, Winchester L, et al.: High-density SNP association study and copy number variation analysis of the AUTS1 and AUTS5 loci implicate the IMMP2L-DOCK4 gene region in autism susceptibility. Mol Psychiatry 2009.

45. Hutcheson HB, Olson LM, Bradford Y, Folstein SE, Santangelo SL, Sutcliffe JS, Haines JL: Examination of NRCAM, LRRN3, KIAA0716, and LAMB1 as autism candidate genes. BMC Med Genet 2004, 5:12.

46. Lord C, Rutter M, Le Couteur A: Autism diagnostic interview-revised: a revised version of a diagnostic interview for caregivers of individuals with possible pervasive developmental disorders. J Autism Dev Disord 1994, 24:659-685

47. Sparrow S, Balla D, Cicchetti D: Vineland Adaptive Behaviour Scales. MN: Allyn \& Bacon; 1984

48. Lord C, Risi S, Lambrecht L, Cook EH Jr, Leventhal BL, DiLavore PC, Pickles A, Rutter M: The autism diagnostic observation schedule-generic: a standard measure of social and communication deficits associated with the spectrum of autism. J Autism Dev Disord 2000, 30:205-223.

49. Mulder EJ, Anderson GM, Kema IP, Brugman AM, Ketelaars CE, de Bildt A van Lang ND, den Boer JA, Minderaa RB: Serotonin transporter intron 2 polymorphism associated with rigid-compulsive behaviors in Dutch individuals with pervasive developmental disorder. Am J Med Genet B Neuropsychiatr Genet 2005, 133B:93-96.
50. Mulder EJ, Anderson GM, Kema IP, de Bildt A, van Lang ND, den Boer JA, Minderaa RB: Platelet serotonin levels in pervasive developmental disorders and mental retardation: diagnostic group differences, withingroup distribution, and behavioral correlates. J Am Acad Child Adolesc Psychiatry 2004, 43:491-499.

51. Barrett JC, Fry B, Maller J, Daly MJ: Haploview: analysis and visualization of LD and haplotype maps. Bioinformatics 2005, 21:263-265.

52. Fiddy S, Cattermole D, Xie D, Duan XY, Mott R: An integrated system for genetic analysis. BMC Bioinformatics 2006, 7:210

53. O'Connell JR, Weeks DE: PedCheck: a program for identification of genotype incompatibilities in linkage analysis. Am J Hum Genet 1998, 63:259-266

54. Abecasis GR, Cherny SS, Cookson WO, Cardon LR: Merlin--rapid analysis of dense genetic maps using sparse gene flow trees. Nat Genet 2002, 30:97-101.

55. Spielman RS, McGinnis RE, Ewens WJ: Transmission test for linkage disequilibrium: the insulin gene region and insulin-dependent diabetes mellitus (IDDM). Am J Hum Genet 1993, 52:506-516.

56. Clayton $\mathrm{D}$, Jones $\mathrm{H}$ : Transmission/disequilibrium tests for extended marker haplotypes. Am J Hum Genet 1999, 65:1161-1169.

57. Kazeem GR, Farrall M: Integrating case-control and TDT studies. Ann Hum Genet 2005, 69:329-335.

58. Normand SL: Meta-analysis: formulating, evaluating, combining, and reporting. Stat Med 1999, 18:321-359.

59. Sebat J, Lakshmi B, Malhotra D, Troge J, Lese-Martin C, Walsh T, Yamrom B, Yoon S, Krasnitz A, Kendall J, et al.: Strong association of de novo copy number mutations with autism. Science 2007, 316:445-449.

60. Risch N: Implications of multilocus inheritance for gene-disease association studies. Theor Popul Biol 2001, 60:215-220.

61. Gabriel SB, Schaffner SF, Nguyen H, Moore JM, Roy J, Blumenstiel B, Higgins J, DeFelice M, Lochner A, et al.: The structure of haplotype blocks in the human genome. Science 2002, 296:2225-2229.

62. Casanova MF, Buxhoeveden DP, Switala AE, Roy E: Minicolumnar pathology in autism. Neurology 2002, 58:428-432.

63. Palmen SJ, van Engeland H, Hof PR, Schmitz C: Neuropathological findings in autism. Brain 2004, 127:2572-2583.

\section{doi: 10.1186/2040-2392-1-7}

Cite this article as: Sousa et al., Polymorphisms in leucine-rich repeat genes are associated with autism spectrum disorder susceptibility in populations of European ancestry Molecular Autism 2010, 1:7 